\title{
Construction of Novel Nanohybrids(Fe304/HAp/Au) With Multifunctional Structure for Efficient Photocatalytic Application
}

Rui Wu ( $\sim$ hftffc@163.com)

Shaanxi University of Technology https://orcid.org/0000-0002-0195-8742

Xiaohui Ji

Shaanxi University of Technology

Donghui Xia

Shaanxi University of Technology

Haitao Xiong

Shaanxi University of Technology

Jiufu Lu

Shaanxi University of Technology

\section{Research Article}

Keywords: Fe304/HAp/Au, nanoparticles, photocatalysis, methylene blue

Posted Date: July 23rd, 2021

DOI: https://doi.org/10.21203/rs.3.rs-735671/v1

License: (c) (i) This work is licensed under a Creative Commons Attribution 4.0 International License.

Read Full License 


\title{
Construction of Novel Nanohybrids $\left(\mathrm{Fe}_{3} \mathrm{O}_{4} / \mathrm{HAp} / \mathrm{Au}\right)$ with Multifunctional Structure for Efficient Photocatalytic Application
}

\author{
Rui Wu*, Xiaohui Ji, Donghui Xia, Haitao Xiong, Jiufu Lu
}

\begin{abstract}
The controlled synthesis of nanohybrids with magnetic metal oxides $\left(\mathrm{Fe}_{3} \mathrm{O}_{4}\right)$, noble metals $\mathrm{Au}$, and hydroxyapatite (HAp, hydroxyapatite) have received considerable attention for applications in photocatalysis, molecular imaging, drug delivery. Green and multifunctional $\mathrm{Fe}_{3} \mathrm{O}_{4} / \mathrm{HAp} / \mathrm{Au}$ composite nanoparticles (NPs) with biocompatibility and magnetism for photocatalyst was developed by a facile method. The overall architecture of nanocomposites is one of the most important factors dictating the physical and chemical properties of nanohybrids with significant advances and various functions. The improvement performance of the $\mathrm{Fe}_{3} \mathrm{O}_{4} / \mathrm{HAp} / \mathrm{Au}$ in photocatalysis was evaluated by degradation of organic pollutant (methylene blue, MB) under visible light irradiation. The results showed that the hybrid $\mathrm{Fe}_{3} \mathrm{O}_{4} / \mathrm{HAp} / \mathrm{Au}$ NP displayed high photocatalytic activity due to surface plasmon resonance (SPR) of Au, the combination of magnetic NPs and HAps with adsorption, also the mechanism was discussed in detail. The efficient magnetic composite nanoparticles can be separated with target and recover, as well as recycle processes. It proposed novel NPs and methodology to design and fabrication of multifunctional NPs with high quality for application of photocatalysis. Furthermore, it is expected that the safe, green and multifunctional composite NPs will provide an interesting platform not only for photocatalysis, but also for developing molecular imaging probe and drug delivery with target, as well as Raman detection.
\end{abstract}

Keywords: $\mathrm{Fe}_{3} \mathrm{O}_{4} / \mathrm{HAp} / \mathrm{Au}$; nanoparticles; photocatalysis; methylene blue

\section{Introduction}

With the swift development of economy, environmental issues was one of the biggest global challenges in 21st century. Environmental problems threaten ecological balance, endanger human health and restrict the sustainable development of our economy and society[1,2,3]. Therefore, it was highly urgent to develop high-efficiency, environment friendly, facile and green methods for environmental remediation. Dye and heavy metal as effluent being released from industry was a significant source of pollution and eutrophication in ecosystems[4-7]. Due to the stringent environmental standards, techniques for the dispose of dye have been intensively developed. Among these technologies, methods such as chemical degradation ${ }^{[8]}$, physical adsorption ${ }^{[9-11]}$ and biodegradation ${ }^{[12-14]}$ have been applied in industry. ${ }^{1}$

As one of the most promising method in harvesting abundant and renewable sunlight of energy production and environmental remediation, photocatalytic technologies offered great potential solar energy for converting photon energy into chemical energy and therefore degrade organic contaminants to purify waste water [15-18]. The photocatalytic technologies has attracted considerable attention for solving environmental matter. To be good photocatalyst, the candidate should be not only efficient in absorbing solar light, but also effective in decreasing the

1Shaanxi Key Laboratory of Catalytic Foundation and Application, College of Chemical \& Environment Science, Shaanxi University of Technology, Hanzhong, 723001, P.R.China

Funded by the Key Scientific Research Program of Shaanxi Provincial Education Department (21JS004) 
recombination of the photogenerated carriers. The past decades have been witnessed a great deal of efforts towards the high quality photocatalyst. NPs catalyst have received growing popularity worldwide, because of the high catalytic activity and the facile method for synthesis. The controlled synthesis of nanoparticles, such as noble metals ( $\mathrm{Au}, \mathrm{Ag}, \mathrm{Pt}$ and $\mathrm{Pd}$ ) and metal oxides ( $\mathrm{ZnO}, \mathrm{TiO}_{2}, \mathrm{Cu}_{2} \mathrm{O}$ and $\mathrm{CeO}_{2}$ ) have attracted significant attention in photocatalysis[19-24]. The catalysis of noble metals, generally known as "foundation pillar" of green chemistry, played crucial role in chemical industry. Particularly, the incorporation of noble metal NPs (Au) can absorb visible light via surface plasmon resonance (SPR) to enhance photocatalytic activity $[25,26]$. Research on solar-driven photocatalysis based on SPR has seen rapid growth and potentially opened a technologically promising. In plasmonic photocatalysis, noble metal NPs often coupled with certain carrier as composite that can offer relatively high specific surface area as well as active sites to enhance the photocatalytic performance. Significant progress has been made to assembly and fabricate plasmonic nanomaterials, such as $\mathrm{Au} / \mathrm{TiO} \mathrm{O}_{2}, \mathrm{Au} / \mathrm{ZrO}_{2}, \mathrm{Au} / \mathrm{CeO}_{2}, \mathrm{Au} / \mathrm{Al}_{2} \mathrm{O}_{3}$. These plasmonic nanostructures demonstrated unique physico-chemical properties that was not only useful in photocatalysis but also in industrial materials.

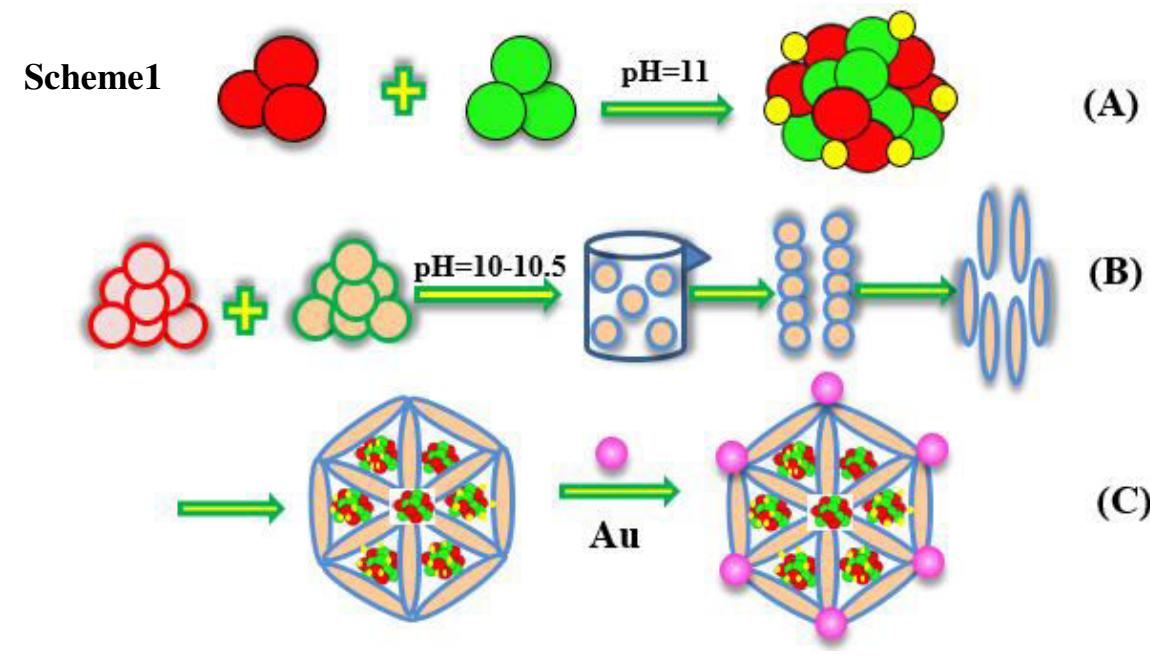

The synthesis of $\mathrm{Fe}_{3} \mathrm{O}_{4} / \mathrm{HAp} / \mathrm{Au}$ composite nanopartic les. A: $\mathrm{Fe}_{3} \mathrm{O}_{4}$, B: HAp, C: $\mathrm{Fe}_{3} \mathrm{O}_{4} / \mathrm{HAp} / \mathrm{Au}$.

Recently, hydroxyapatite (HAp) and Au NPs have been attracted great interest in a variety of applications owing to their crystal structure and biocompatibility. HAp has been reported in removal of a wide variety of metals $(\mathrm{Cu}, \mathrm{Cr}, \mathrm{Co}, \mathrm{Cd}, \mathrm{Zn}, \mathrm{Ni}, \mathrm{Pb}, \mathrm{As}, \mathrm{Sb}$ and $\mathrm{Sr})$, nonmetal $(\mathrm{F})$ and dye, owing to their crystal structure which is hexagonal, essentially a 6 -fold c-axis perpendicular to three equivalent a-axes at angles of $120^{\circ}$,with space group $\mathrm{P} 63 / \mathrm{m}[27,28,29]$. Extensive research of photocatalysis on Au have been carried out, the SPR associated photoreactivity of mechanism was rigorously established. In this paper, we synthesized HAp loaded small Au NPs as photocatalyst combined the three types of nanomaterials. Furthermore, magnetic $\mathrm{Fe}_{3} \mathrm{O}_{4} \mathrm{NPs}$ were also employed as carrier with convenience of seperation and recycle. Herein, we accessed the hybrid nanocomposite of $\mathrm{Fe}_{3} \mathrm{O}_{4} / \mathrm{HAp} / \mathrm{Au}$ as to investigate the photocatalysis. $\mathrm{MB}$ was acted as typical model compounds to investigate the photocatalytic activities of the $\mathrm{Fe}_{3} \mathrm{O}_{4} / \mathrm{HAp} / \mathrm{Au}$ under visible light irradiation. The synthesis of $\mathrm{Fe}_{3} \mathrm{O}_{4} / \mathrm{HAp} / \mathrm{Au}$ composite NPs is in scheme 1.

\section{Materials and methods}

\subsection{Materials}

Calcium nitrate tetrahydrate $\left(\mathrm{Ca}\left(\mathrm{NO}_{3}\right)_{2} .4 \mathrm{H}_{2} \mathrm{O}\right)$, disodium hydrogen phosphate $\left(\mathrm{Na}_{2} \mathrm{HPO}_{4}\right)$, 
ammonium hydroxide $\left(\mathrm{NH}_{4} \mathrm{OH}\right)$ and gold (III) chloride trihydrate $\left(\mathrm{HAuCl}_{4}\right)$ were purchased from Sigma-Aldrich. Ferrous sulfate $\left(\mathrm{FeSO}_{4}\right)$, ferrous sulfate $\left(\mathrm{FeCl}_{3} \cdot 6 \mathrm{H}_{2} \mathrm{O}\right)$ and $\mathrm{MB}$ were produced from Tianjin Kemiou Chemical Reagent Co., Ltd. Polyethyleneimine (PEI) and sodium borohydride were obtained from Sinopharm Chemical Reagent Co., Ltd. All these chemicals were analytical grade and used without further purification. Ultrapure water was from millipore water purification system.

\subsection{Preparation of materials}

Synthesis of $\mathrm{Fe}_{3} \mathrm{O}_{4}$ NPs: The $\mathrm{Fe}_{3} \mathrm{O}_{4}$ NPs were prepared by coprecipitation with $\mathrm{Fe}(\mathrm{II})$ and $\mathrm{Fe}$ (III) (FeII/FeIII ratio of 0.5) in an alkaline solution. Briefly, ferrous sulfate and ferric chloride were accurately weighed and dissolved deoxygenated water in the presence of nitrogen with stirring vigorously. Subsequently, ammonium hydroxide was added dropwise into the mixture and adjusted the $\mathrm{pH}$ of the solution to be maintained at 10 11. Pale yellow solution changed to brown and became dark black. Finally, the water bath kept at $60{ }^{\circ} \mathrm{C}$ for half an hour. After $30 \mathrm{~min}$, the temperature was set at $80^{\circ} \mathrm{C}$ and aged for $30 \mathrm{~min}$. Then, separation was carried out with magnet and washed with deionized water.

Synthesis of magnetic hydroxyapatite $\left(\mathrm{Fe}_{3} \mathrm{O}_{4} / \mathrm{HAp}\right) \mathrm{NPs}$ : Typically, $0.2 \mathrm{~g}$ of synthesized $\mathrm{Fe}_{3} \mathrm{O}_{4} \mathrm{NPs}$ above was added to $0.1 \mathrm{M}$ of disodium hydrogen phosphate, ultrasonic dispersion for 10 min and adjusted $\mathrm{pH}$ to $10-11$ with ammonium hydroxide. Calcium nitrate was slowly dropwise introduced into the solution and stirred mechanically for $1 \mathrm{~h}$. The resulting suspension was aged for $24 \mathrm{~h}$ without stirring. The obtained precipitate was separated by magnet and washed repeatedly with deionized water.

Preparation of $\mathrm{Au}$ seed solution: Briefly, $1 \mathrm{~mL}$ of $1 \% \mathrm{HAuCl}_{4}$ was added to $90 \mathrm{~mL}$ of ultrapure water at room temperature under magnetic stirring. $2.00 \mathrm{~mL}$ of $1 \%$ sodium citrate was added as dispersant. After one minute, $1.00 \mathrm{~mL}$ of fresh $0.075 \% \mathrm{NaBH}_{4}$ in $1 \%$ sodium citrate was added quickly. The solution became wine red instantly which indicated the presence of Au NPs. The colloidal solution of Au was stirred for $5 \mathrm{~min}$ and stored in brown bottle at $4{ }^{\circ} \mathrm{C}$.

Synthesis of $\mathrm{Fe}_{3} \mathrm{O}_{4} / \mathrm{HAp} / \mathrm{Au}$ composite NPs: The prepared of magnetic hydroxyapatite $\left(\mathrm{Fe}_{3} \mathrm{O}_{4} / \mathrm{HAp}\right)$ nanoparticles was dispersed in ultrapure water. Then, a certain amount of PEI was added and ultrasond for $15 \mathrm{~min}$. The $\mathrm{Fe}_{3} \mathrm{O}_{4} / \mathrm{HAp}$ NPs was separated by magnet to remove free PET and washed with deionized water. The obtained production was dispersed in ultrapure water again and the Au seed solution was added, stirred for $30 \mathrm{~min}$. Followed by separation with magnet to remove free $\mathrm{Au}$ seed.

\subsection{Characterization}

The crystal structure and phase purity of the composite NPs were examined with X-ray diffraction (XRD). It was recorded with a $2 \theta$ range of $10^{\circ}-80^{\circ}$ by $\mathrm{Cu} \mathrm{K} \alpha(\lambda=0.15406 \mathrm{~nm})$ in steps of $0.05^{\circ} \mathrm{min}^{-1}$. The accelerating voltage and applied current were $36 \mathrm{kV}$ and $20 \mathrm{~mA}$, respectively. The magnetic properties of $\mathrm{Fe}_{3} \mathrm{O}_{4} / \mathrm{HAp} / \mathrm{Au}$ NPs were measured with a Quantum Design Magnetic Properties Measurement System (MPMS) XL-7 with Superconducting Quantum Interference Device (SQID) at room temperature. The absorption spectra of Au NPs was recorded by a UV-vis spectrophotometer. The morphology and structure of the as-synthesized $\mathrm{Fe}_{3} \mathrm{O}_{4} / \mathrm{HAp} / \mathrm{Au}$ NPs were investigated by TEM. TEM images were recorded using FEI Tecnai G2 S-Twin type with a field emission gun operating at $200 \mathrm{kV}$. The aqueous suspension of the NPs was droped onto a carbon-coated copper grid, and the grid was air-dried at room temperature.The morphology and 
lattice fringes of $\mathrm{Fe}_{3} \mathrm{O}_{4} / \mathrm{HAp} / \mathrm{Au}$ NPs were examined.

\subsection{MB degradation}

The photocatalytic activity of the $\mathrm{Fe}_{3} \mathrm{O}_{4} / \mathrm{HAp} / \mathrm{Au}$ NPs was monitored by degradation of MB dye. Typically, $20 \mathrm{mg}$ of $\mathrm{Fe}_{3} \mathrm{O}_{4} / \mathrm{HAp} / \mathrm{Au}$ NPs was added to $50 \mathrm{~mL}$ of $\mathrm{MB}(20.0 \mathrm{mg} / \mathrm{L})$ solution with stirring in dark in order to establish an adsorption-desorption equilibrium. After complete adsorption of MB, the whole mixture was degraded. The photocatalytic activity of the hybrid catalysts was monitored by the degradation of MB under irradiation with visible light using a 500 W xenon lamp at room temperature. Typically, the reaction solution was then stirred under visible-light irradiation for several minutes. At given time intervals, sample was separated with magnet. The supernatant was tested by measuring the absorbance at $664 \mathrm{~nm}$ using a UV-Vis spectrophotometer. Control experiment was also carried out in the absence of Au.

\section{Results}

\subsection{Characterization}

Fig.1

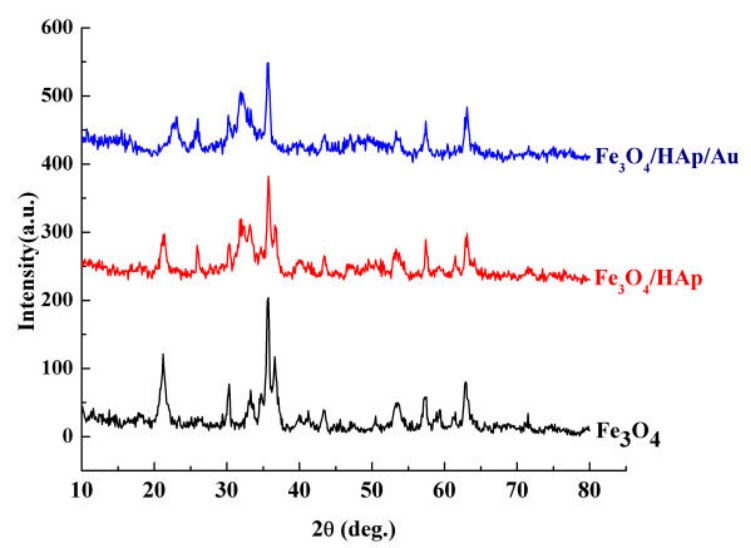

XRD analysis of $\mathrm{Fe}_{3} \mathrm{O}_{4}$ and $\mathrm{Fe}_{3} \mathrm{O}_{4} / \mathrm{HAp}$

The X-ray diffraction patterns of the NPs was shown in Fig. 1. The XRD patterns of the final products contained well-defined peaks corresponding to the standard carbonate apatite (JCPDS). The diffraction intensity of the peak corresponding to the (111) plane of standard was in Fig. 1. These X-ray diffraction data were coincided with reported values well. As shown in Fig. 2, for the $\mathrm{Fe}_{3} \mathrm{O}_{4} / \mathrm{HAp} / \mathrm{Au}$ samples, the coercivity force was almost negligible at $300 \mathrm{~K}$, which indicated that $\mathrm{Fe}_{3} \mathrm{O}_{4} / \mathrm{HAp} / \mathrm{Au}$ NPs was magnetic at room temperature. It can be calculated that the saturation magnetization of $\mathrm{Fe}_{3} \mathrm{O}_{4} / \mathrm{HAp} / \mathrm{Au}$ NPs was about $50 \mathrm{emu} / \mathrm{g}$ (curve a). The strong magnetization of the hybrid NPs should facilitate in magnetic separation, hyperthermia, catalysis carrier, and drug delivery with biocompatibility. 


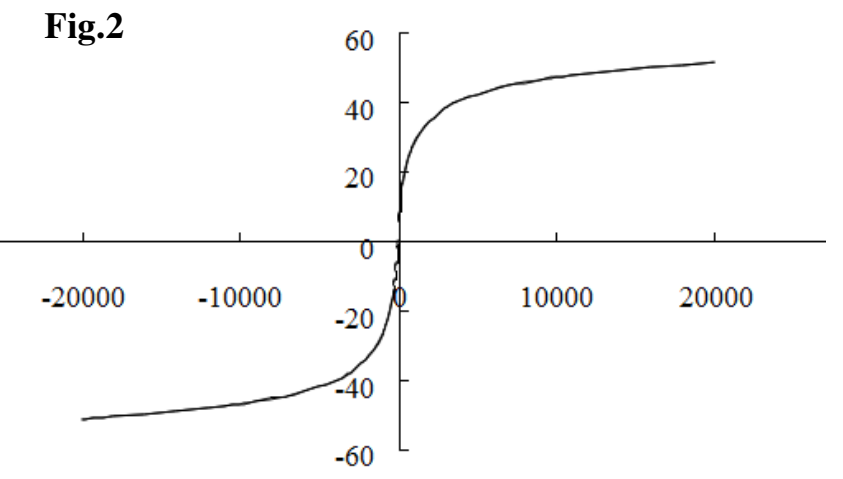

Room temperature magnetization curves of $\mathrm{Fe}_{3} \mathrm{O}_{4} / \mathrm{HAp} / \mathrm{Au}$ nanopartic les

TEM was a common method for characterization of NPs in morphological and microstructural analysis. The $\mathrm{Fe}_{3} \mathrm{O}_{4} \mathrm{NRs}$ had a uniform and well-defined structure with an average radius of $8 \mathrm{~nm}$, but with poor dispersibility due to the strong magnetism in Fig 3(a). As shown in Fig 3(b), the HAp was typically rodlike shape, with an average length of $50 \mathrm{~nm}$. The TEM images confirmed the obtained products of hybrid $\mathrm{Fe}_{3} \mathrm{O}_{4} / \mathrm{HAp} / \mathrm{Au}$ in Fig 3(c). The dark black was Au NPs due to the high atomic number. From the TEM imaging, it indicated that the Au as catalyst was loaded on the $\mathrm{Fe}_{3} \mathrm{O}_{4} / \mathrm{HAp}$ NPs because of the strong complexation between amino of PEI and Au. Interplanar distance was measured from the atomic planes and revealed the formation of predominant (111) planes of Au in body-centered cubic phase (lattice spacing of $0.235 \mathrm{~nm}$ ) in the HRTEM image in Fig 3(d). Fig. 4 showed the UV-vis spectra of the Au particles. The original Au colloid exhibited a maximum absorption peak at $520 \mathrm{~nm}$.

Fig.3

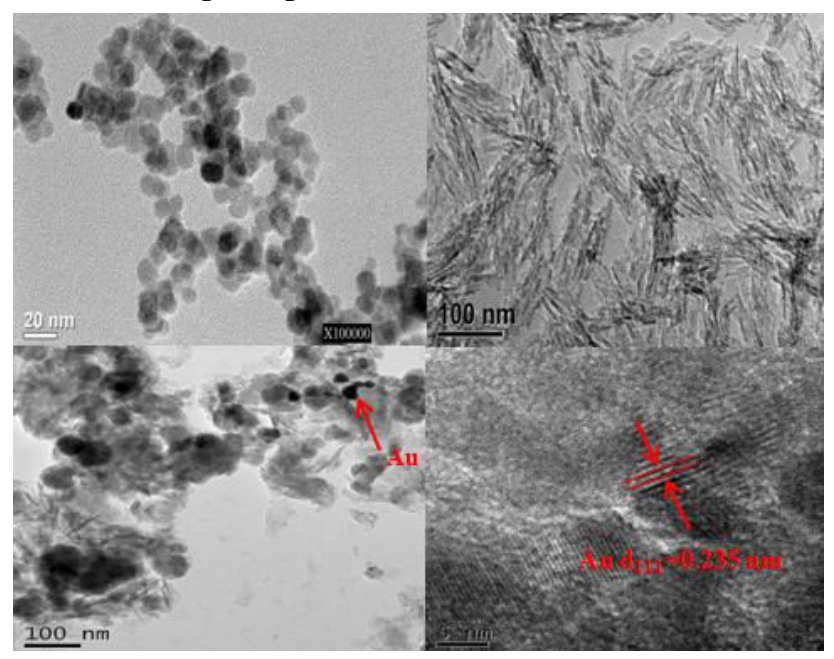

TEM imaging of $\mathrm{Fe}_{3} \mathrm{O}_{4}$ (a), $\mathrm{HAp}(\mathrm{b}), \mathrm{Fe}_{3} \mathrm{O}_{4} / \mathrm{HAp} / \mathrm{Au}$ (c) and HRTEM of $\mathrm{Fe}_{3} \mathrm{O}_{4} / \mathrm{HAp} / \mathrm{Au}$ (d) 


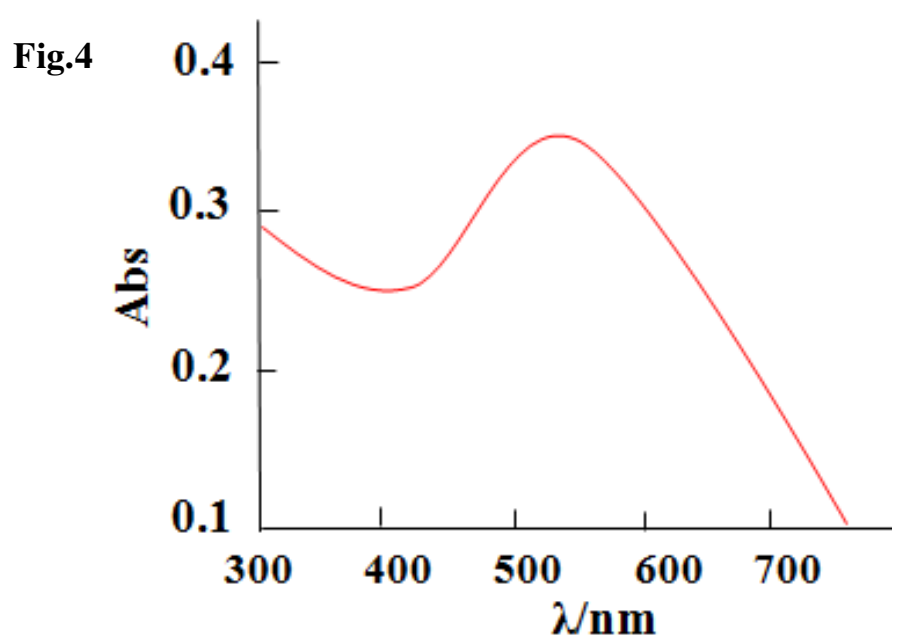

UV-vis absorption spectra of the Au nanoparticle

\subsection{Photocatalysis}

Fig.5

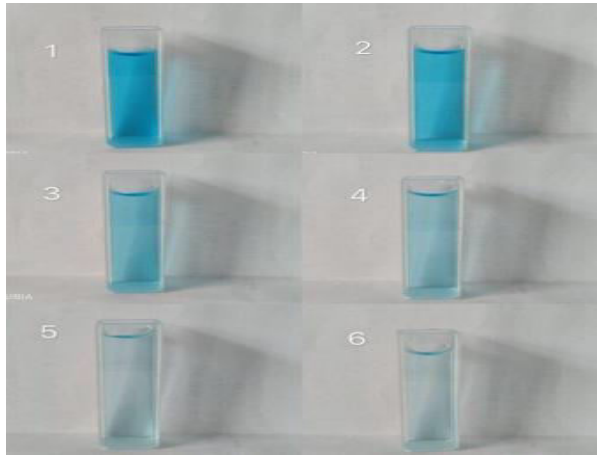

The color changed in the process of photocatalys is

In order to study the $\mathrm{MB}$ degradation by $\mathrm{Fe}_{3} \mathrm{O}_{4} / \mathrm{HAp} / \mathrm{Au}$ occurring with visible light, it was important to investigate the influence of adsorption, xenon lamp and Au in Fig. 6. The colour of the MB gradually turn transparent during the degradation process in Fig. 5. In Fig. 6(A), there was scarcely degradation of $\mathrm{Fe}_{3} \mathrm{O}_{4} / \mathrm{HAp} / \mathrm{Au}$ without xenon lamp. However, the adsorption of $\mathrm{MB}$ occured over $\mathrm{Fe}_{3} \mathrm{O}_{4} / \mathrm{HAp}$ via irradiation without $\mathrm{Au}$ in Fig. 6(B). The strong absorption bands of MB located at $\lambda=664 \mathrm{~nm}$ decreased gradually along with the irradiation time, and the absorbance almost unchanged after $1 \mathrm{~h}$. 
Fig.6
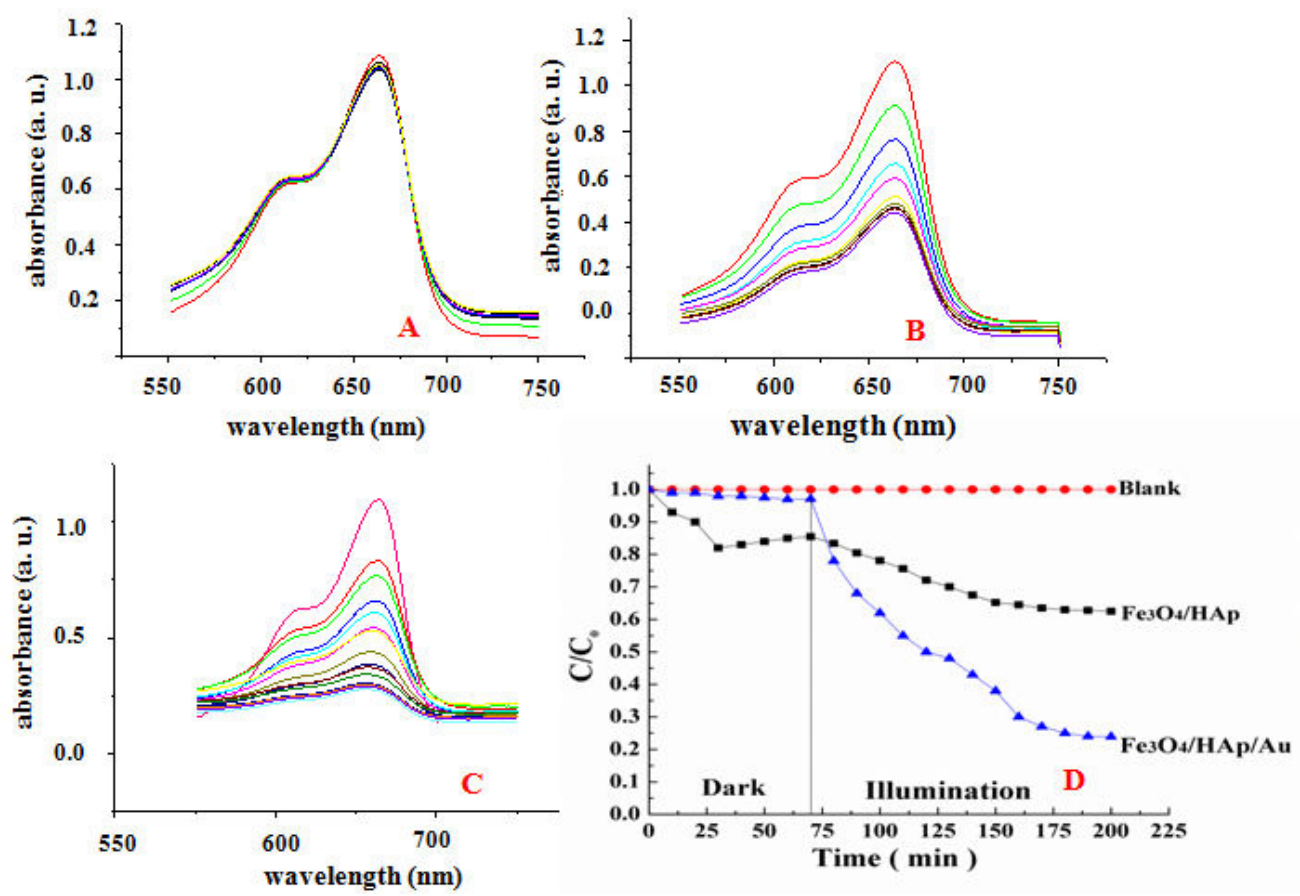

The process of degradation over the $\mathrm{Fe}_{3} \mathrm{O}_{4} / \mathrm{HAp} / \mathrm{Au}$ catalyst

The photocatalytic behave of the $\mathrm{Fe}_{3} \mathrm{O}_{4} / \mathrm{HAp} / \mathrm{Au}$ was further evaluated with the performance of $\mathrm{Au}$ and xenon lamp, as shown in Fig. 6(C). Fortunately, the photocatalysis of $\mathrm{Fe}_{3} \mathrm{O}_{4} / \mathrm{HAp} / \mathrm{Au}$ for MB performed perfectly with xenon lamp. The strong absorption bands of MB located at $\lambda=$ $664 \mathrm{~nm}$ decreased obviously. It was demostrated that $\mathrm{Fe}_{3} \mathrm{O}_{4} / \mathrm{HAp} / \mathrm{Au}$ was excellent photocatalyst for MB in the presence of xenon lamp. In addition, the strong absorption bands of MB hardly shift, it was indicated that the degradation of $\mathrm{MB}$ was account for the chromophore being destroyed. The relationship between absorbance and irradiation time of MB degradation was shown in Fig. 6(D). Photodegradation curve of MB solution for $\mathrm{Fe}_{3} \mathrm{O}_{4} / \mathrm{HAp}$ and Au-loaded $\mathrm{Fe}_{3} \mathrm{O}_{4} / \mathrm{HAp}$ samples were presented, $C / C_{0}$ versus time, where $C_{0}$ was the initial concentration of the dye and $C$ was concentration of $\mathrm{MB}$ at particular time. As can be seen, the absorption of $\mathrm{MB}$ for $\mathrm{Fe}_{3} \mathrm{O}_{4} / \mathrm{HAp}$ was occured both in dark and illumination. The $\mathrm{Fe}_{3} \mathrm{O}_{4} / \mathrm{HAp} / \mathrm{Au}$ exhibited excellent catalytic activity for MB under visible-light irradiation. It is clearly seen that the color of the MB solution chnaged from blue to light in the process of photocatalysis.

\section{Mechanism of MB degradation}

$$
\begin{aligned}
& \mathrm{O}_{2}+\mathrm{e}^{-} \rightarrow \mathrm{O}_{2} \cdot \\
& \mathrm{O}_{2}{ }^{\cdot}+\mathrm{H}^{+} \rightarrow \mathrm{HO}_{2}{ }^{+}+\mathrm{OH}^{\cdot} \\
& 2 \mathrm{OH}^{\cdot} \rightarrow \mathrm{H}_{2} \mathrm{O}_{2} \\
& \mathrm{H}_{2} \mathrm{O}_{2}+\mathrm{e}^{-} \rightarrow \mathrm{OH}^{-}+\mathrm{OH}^{\cdot} \\
& \mathrm{MB}+\mathrm{HO}_{2}{ }^{\cdot}+\mathrm{OH}^{\cdot}+\mathrm{O}_{2} \cdot \rightarrow\left(\mathrm{CO}_{2}+\mathrm{H}_{2} \mathrm{O}+\mathrm{NO}_{3}+\mathrm{Cl}^{-}+\mathrm{SO}_{4}{ }^{2-}\right)
\end{aligned}
$$


Scheme.2
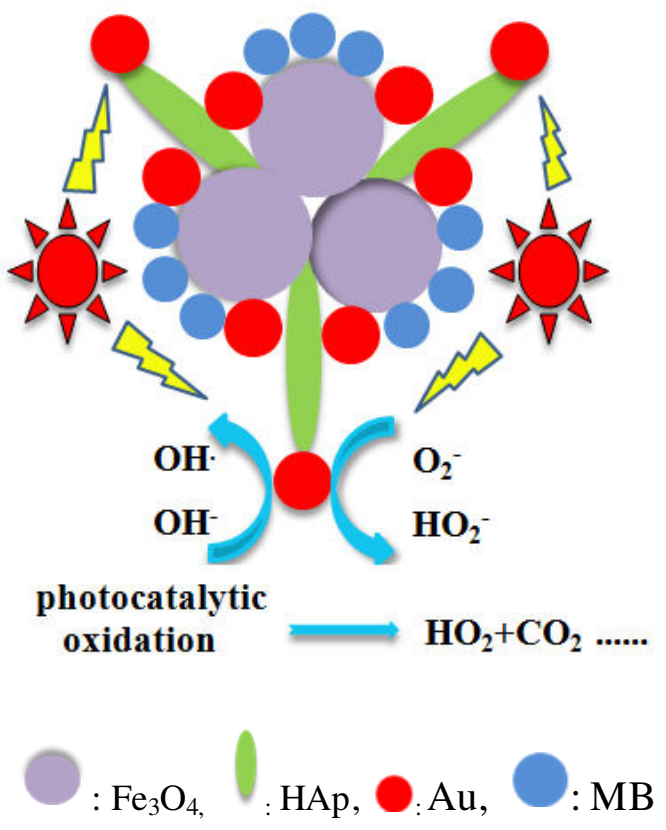

Schematic presentation of the photocatalytic degradation process induced by $\mathrm{Fe}_{3} \mathrm{O}_{4} / \mathrm{HAp} / \mathrm{Au}$

Surface plasmon resonance (SPR) played an important role to enhance photocatalytic activity. In plasmonics, nanomaterials were often employed to manipulate and control light precisely on nanometer range. Especially the nanomaterials loading noble metal NPs ( $\mathrm{Au}, \mathrm{Ag})$ can absorb visible light via SPR to enhance photocatalytic activity ${ }^{[34-35]}$. In the process of photocatalytic reaction with $\mathrm{Au}, \mathrm{Au}$ NPs adsorbed photons through the SPR effect. The UV-Vis spectra of $\mathrm{Fe}_{3} \mathrm{O}_{4} / \mathrm{HAp} / \mathrm{Au}$ appeared at $525 \mathrm{~nm}$, originating from the intraband excitation of 6sp electrons. Then, photogeneration electron transfer occured from Au NPs to $\mathrm{Fe}_{3} \mathrm{O}_{4} / \mathrm{HAp}$. The positive charge $\mathrm{Au}$, under the illumination of visible light resulted in Au's 6sp band. While $\mathrm{O}_{2}$ molecules on the Au nanoparticles obtained the electrons of the excited energy levels of Au's 6sp band to form peroxide radical anion $\mathrm{O}_{2}$. Peroxide radical anion was a key precursor for the generation of active species enabling the degradation of dye. Also, the $\mathrm{O}_{2} \cdot$ reacted with $\mathrm{H}^{+}$ions from water to generate active species such as $\mathrm{HO}_{2}^{\circ}, \mathrm{OH}, \mathrm{H}_{2} \mathrm{O}_{2}$. Furthermore, $\mathrm{Fe}_{3} \mathrm{O}_{4} / \mathrm{HAp}$ loaded Au can attracted electrons from the dye on the nanoparticles which accelerate catalyze the MB. The mechanism of MB degradation was presented in the equation above and in scheme 2, respectively.

\section{Conclution}

A new type of SPR photocatalyst was fabricated, where Au was incorporated on the $\mathrm{Fe}_{3} \mathrm{O}_{4} / \mathrm{HAp}$ NPs, formed hybrid $\mathrm{Fe}_{3} \mathrm{O}_{4} / \mathrm{HAp} / \mathrm{Au}$. The as-prepared $\mathrm{Fe}_{3} \mathrm{O}_{4} / \mathrm{HAp} / \mathrm{Au}$ catalyst was characterized by TEM, XRD and MPMS. In general, the associated of $\mathrm{Au}$ on $\mathrm{Fe}_{3} \mathrm{O}_{4} / \mathrm{HAp}$ NPs surface increased its active site of catalysis. The fabricated of $\mathrm{Fe}_{3} \mathrm{O}_{4} / \mathrm{HAp} / \mathrm{Au}$ showed a signicant photocatalytic performance to MB under visible light illumination due to the SPR of Au. The SPR mediated photocatalysis was key to enable technology breakthroughs, and potentially broadened implications that cross biotechnology, single molecule spectroscopy, and Raman spectroscopy. In addition, the usage of plasmonic noble metal NPs Au with great promise in photocatalysis, make it widespread applications for human beings. The nontoxic, biocompatible, eco-friendly, renewable and green SPR mediated photocatalysis is not only a new thrust in solving environmental problem, but also sustainability of global development in the future. 


\section{Acknowledgments}

We greatly appreciated the support of the Key Scientific Research Program of Shaanxi Provincial Education Department(21JS004)..

\section{References}

[1] P. Moriarty. Environ. Sci. Technol. 49, 5255-5296(2015).

[2] E. Olkowska, Z. Polkowska Ż and J. Namieśnik. Chem. Rev. 111, 5667-5700(2011).

[3] P. M. Pakdel, S. J. Peighambardoust. Environ. Manage. 217,123-143(2018).

[4] R. J. Zhu, Y. H. Xu, Q. Bai. Chem. Phys. Lett. 702, 26-31(2018).

[5] S. Natarajan, H. C. Bajaj, R. J. Tayade. J. Environ. Sci. 65, 201-222(2018).

[6] P. Chen, X. Xing, H. F. Xie. Chem. Phys. Lett. 660,176-181(2016).

[7] M. M. Luan, G. L. Jing, Y. J. Piao. Arab. J. Chem.10, 769-776(2017).

[8] S. Lee, A. Stubelius, J. Olejniczak J. Biomater. Sci. 6, 107-114(2018).

[9] Y. Hong, Z. L. Gao, M. J. Chen. Langmuir. 32, 9435-9441(2018).

[10] S. Lu, Y. L. Wang, F. Li. J. Phys. Chem. C. 121, 12524-12530(2017).

[11] X. P. Wang, C. Hou, W. Qiu. ACS Appl.Mater. Interfaces. 9, 684-692(2017).

[12] M. B. Kurade, T. R. Waghmode, M. U. Jadhav. RSC Adv. 5, 30021(2015).

[13] M. Z. Khan, S. Singh, T. R. Sreekrishnan. RSC Adv. 4, 46851-46859(2014) .

[14] J. H. Wang, T. Ding and K. F. Wu. J. Am. Chem. Soc. 140, 10117-10120(2018).

[15] N. Micic and A. Polyzos. Org. Lett. 20, 4663-4666(2018).

[16] S. S. Mandal, A. J. Bhattacharyya. Talanta, 82, 876-884(2010).

[17] M. J. James, J. L. Schwarz, F. S. Kalthoff F. J. Am. Chem. Soc., 140, 8624-8628(2018).

[18] D. A. Nelson and Z. D. Schultz Z D. J. Phys. Chem. C. 122, 8581-8588(2018).

[19] R. Wu, L. Hao, X. H. Yu X H. J.Wuhan University of Technology-Mater. Sci. Ed. 34, 900-905(2019).

[20] T. C. Zhang, D. Zhen, B. Y. Liang. J Inorg Organomet P. 31, 303-310(2021).

[21] L. Amal. A. Alotaibi, N. Altamimi, E. Howsawi. J Inorg Organomet P. 31, 2017-2020(2021).

[22] A. M. Lacerda, I. Larrosa and S. Dunn . Nanoscale. 7, 12331-12335(2015).

[23] L. F. Wang, S. H. Liu, Z. Wang. ACS Nano. 10, 2636-2643(2018).

[24] W. Y. Lei, T. T. Zhang, L. Gu L. ACS Catal. 5, 4385-4393(2015).

[25] C. F. Tan, A. K. S. Zin, Z. H. Chen Z H. ACS Nano. 12, 4512-4520(2018).

[26] D. W. Ding, K. Liu, S. N. He. Nano Lett. 14, 6731-6736(2014).

[27] J. Xu, T. White, P. Li. J. Am. Chem. Soc. 132, 13172-13173(2010) .

[28] R. Wu, J. F. Lu, J. Song, C. F. Liu. Chinese J. Org. Chem., 35, 891-900(2019).

[29] S. Mondal, M. E. Reyes, U. Pal. RSC Adv. 7, 8633-8645(2017).

\section{Affiliations}

Shaanxi Key Laboratory of Catalytic Foundation and Application, College of Chemical \& Environment Science, Shaanxi University of Technology, Hanzhong, 723001, P.R.China

\section{Corresponding author}

Rui Wu, associatate professor. E-mail: hftffc@163.com

\section{Conflict of interest}

The authors declare that there is no conflict of interest regarding the publication of this paper. 